\title{
Application of cryopreservation to genetic analyses of a photosynthetic picoeukaryote community
}

Masanobu Kawachi ${ }^{\text {ab* }}$, Takafumi Kataoka ${ }^{\mathrm{ab}}$, Mayumi Sato ${ }^{\mathrm{a}}$, Marie-Hélène Noël ${ }^{\mathrm{a}}$, Akira Kuwata ${ }^{\mathrm{bc}}$, Mikihide Demura ${ }^{\mathrm{d}}$, Haruyo Yamaguchi ${ }^{\mathrm{ab}}$

${ }^{a}$ Center for Environmental Biology and Ecosystem Studies, National Institute for Environmental Studies, 16-2 Onogawa, Tsukuba, Ibaraki 305-8506, Japan

b JST, CREST, 4-1-8 Hon-cho, Kawaguchi, Saitama 332-0012, Japan

${ }^{\mathrm{c}}$ Tohoku National Fisheries Research Institute, Shinhama-cho 3-27-5, Shiogama, Miyagi 985-0001, Japan

${ }^{\mathrm{d}}$ Faculty of Life and Environmental Sciences, University of Tsukuba 1-1-1 Tennodai, Tsukuba, Ibaraki 305-8572, Japan

*Corresponding author:

E-mail address: kawach9i@nies.go.jp (M. Kawachi)

\begin{abstract}
Cryopreservation is useful for long-term maintenance of living strains in microbial culture collections. We applied this technique to environmental specimens from two monitoring sites at Sendai Bay, Japan and compared the microbial diversity of photosynthetic picoeukaryotes in samples before and after cryopreservation. Flow cytometry (FCM) showed no considerable differences between specimens. We used 2,500 cells sorted with FCM for next-generation sequencing of 18S rRNA gene amplicons and after removing low-quality sequences obtained 10,088-37,454 reads. Cluster analysis and comparative correlation analysis of observed high-level operational taxonomic units indicated similarity between specimens before and after cryopreservation. The effects of cryopreservation on cells were assessed with representative culture strains, including fragile cryptophyte cells. We confirmed the usefulness of cryopreservation for genetic studies on environmental specimens, and found that small changes in FCM cytograms after cryopreservation may affect biodiversity estimation.
\end{abstract}

\section{Keywords}

18S rRNA gene; 454 pyrosequencing; Cryopreservation; Photosynthetic picoeukaryotes 


\section{Introduction}

Photosynthetic picoeukaryotes have a cell diameter of less than 2-3 $\mu \mathrm{m}$ (Vaulot et al., 2008). Many recent genetic studies have indicated the existence of a large number of unknown organisms in the pico-size fractions of ocean specimens, suggesting high biodiversity (Massana, 2011). In the open ocean, photosynthetic picoeukaryotes are typically much less abundant than photosynthetic picosized prokaryotes such as Prochlorococcus and Synechococcus (Worden and Not, 2008). However, small eukaryotic phytoplankton, including photosynthetic picoeukaryotes, contributes up to $44 \%$ of total $\mathrm{CO}_{2}$ fixed in the oceans because of their large cell volume and thus higher cell-specific $\mathrm{CO}_{2}$ fixation rates than those of Prochlorococcus and Synechococcus (Jardillier et al., 2010). The high biodiversity may indicate the diversified, but as yet poorly understood, ecological roles of photosynthetic picoeukaryotes (such as mixotrophic ability, symbiotic relationships with other microorganisms, nutritional assimilation and so on). In contrast to the fast accumulation of sequencing data on unknown unculturable microorganisms, there are very few culture strains of photosynthetic picoeukaryotes (Vaulot et al., 2008; Not et al., 2009).

Flow cytometry (FCM) is a useful and powerful tool for distinguishing microorganisms according to their cell sizes and the presence or absence of photosynthetic pigments. FCM cell sorting allows the separation of photosynthetic and non-photosynthetic organisms to better assess the diversity of photosynthetic eukaryotes (Marie et al., 2010). The efficiency of this approach depends on the concentration of the target cells. Sample concentration before sorting-especially in the case of ocean specimens with low cell density - is essential (Marie et al., 2010). The morphology of FCMsorted cells from ocean specimens has been studied with scanning electron microscopy (GömezPereira et al., 2013; Hamdi et al., 2015). FCM sorting, especially in combination with other techniques, may lead to breakthroughs in our understanding of the biodiversity and ecological roles of microorganisms including photosynthetic picoeukaryotes.

Techniques for cryopreservation of cultivated cells have been developed for microbial culture collections to achieve stable and long-term preservation of the strains (Morris, 1981; Mori et al., 2002; Day, 2004). Once viability during cryopreservation is achieved, storage in liquid nitrogen allows preservation of morphological, physiological, biochemical, and genetic properties. Although not all species can be cryopreserved at present, this approach may be applicable to environmental specimens containing diverse microorganisms and intended for genetic studies or establishment of culture strains. Biodiversity of microorganisms in environmental specimens changes quickly after sample collection (Mangot et al., 2013); therefore, cryopreservation would be useful for studies of microorganism biodiversity. The aim of this study was to assess the feasibility of cryopreservation for genetic studies of environmental specimens.

\section{Material and Methods}

\section{1. Sampling and sample treatments}

Samples were collected at two sites, C5 $\left(38^{\circ} 04^{\prime} \mathrm{N}, 141^{\circ} 08^{\prime} \mathrm{E}\right)$ and $\mathrm{C} 12\left(38^{\circ} 11^{\prime} \mathrm{N}, 141^{\circ} 32^{\prime} \mathrm{E}\right)$, in Sendai Bay (Miyagi Prefecture, Japan) on 7 October and 1 December 2013. Seawater was collected with a Niskin bottle from the sea surface $(1 \mathrm{~m})$ and pre-filtered through a plankton net $(5 \mu \mathrm{m}$ mesh size) to remove large plankton. Cells in the filtrate were concentrated $100 \times$ by tangential flow filtration (Vivaflow 200 cartridge equipped with a 100,000 MWCO RC membrane; Sartorius, Germany). 
Dimethyl sulphoxide (DMSO; Nakarai Techs Co., Ltd., Japan) as a cryoprotectant was filter-sterilized in sterile sea water to a final concentration of $10 \%$ using $0.20 \mu \mathrm{m}$ sterile syringe filter (Millex-LG; Millipore, USA). An aliquot (1 ml) of each sample prepared in 10-20 cryovials was mixed with 10\% (v/v) DMSO solution (final concentration 5\%) and cooled from room temperature to $-35^{\circ} \mathrm{C}$ at a rate of $-1{ }^{\circ} \mathrm{C} \mathrm{min}{ }^{-1}$ in a programmable freezer (Bio-Cool IV; FTS Systems, USA). This was followed by cryopreservation at $-196{ }^{\circ} \mathrm{C}$ in liquid nitrogen (2-step freezing method; Morris, 1981; Mori et al., 2002). Another aliquot was immediately analyzed by flow cytometer (see detail in the next section). In another day, the cryopreserved samples were thawed at $40{ }^{\circ} \mathrm{C}$ in a water bath and analyzed immediately. Those samples were named C05NF and C12NF (non-frozen, fresh), and C05F and C12F (frozen, cryopreserved). The procedures from sample collection to amplicon analysis are summarized in Fig. 1.

\section{2. Flow cytometry and photosynthetic picoeukaryote cell sorting from cryopreserved and fresh samples}

A flow cytometer (EPICS ALTRA; Beckman Coulter, Germany) equipped with a cell sorter and an argon laser (excitation at a wavelength of $488 \mathrm{~nm}$ ) was used to analyze specimens. For each cell, three optical parameters were detected by photo-multiplier tubes (PMT): two diffraction parameters, forward-angle scatter (FS, related to the particle size) and side-angle scatter, measured with the PMT1 (SS/PMT1, related to the granularity); and a fluorescence parameter, namely emission in the red (675 $\pm 30 \mathrm{~nm}$ band pass filter), measured with the PMT5 (PMT5, detection of chlorophyll $a$ fluorescence). The picoplankton fraction $(<3 \mu \mathrm{m})$ was selected by comparing the SS of the PMT5-positive cells with that of fluorescent beads (3- $\mu$ m diameter, Flow-Set Pro, A63942; Beckman Coulter, Germany) on the cytogram (Fig. 2), and 2,500 cells were sorted into a 0.2-ml PCR tube. Flow cytometric data were recorded as listmode files and analyzed by using EXPO32 v1.2 Analysis software.

\section{3. Whole-genome amplification, construction of 18S rRNA gene library and sequencing}

Each sample was subjected to alkaline lysis and neutralization (Zhang et al., 1992) and an aliquot was amplified with Genomiphi V2 (GE Healthcare Life Sciences, USA), which uses Phi29 DNA polymerase, known for its extremely low error rate $\left(1 \times 10^{-5}\right.$ after 1,000-fold amplification; Paez et al., 2004). The amplified genomic DNAs were purified by ethanol precipitation and dissolved in TE buffer (Nippon Gene, Japan). For amplification of eukaryotic 18S rRNA genes, we designed a set of primers: $\quad 545 \mathrm{~F} \quad$ (5'-AGGCGCGTAAATTACCCAATC-3') and 1119R (5'TCCCCTAACTTTCGTTCTTG-3'). PCR was performed with Phusion High-Fidelity DNA polymerase (New England BioLabs, USA) and a set of fusion primer attached to a multiplexidentifier (MID) sequence. Specific amplification was confirmed by agarose gel electrophoresis with a molecular size marker. Amplicons of ca. 580 bp were extracted from agarose gel and purified with a QIAquick Gel Extraction Kit (Qiagen, Germany). The quality and fragment length of amplicons were analyzed with a Bioanalyzer (Agilent, USA) using a High sensitivity DNA kit (Agilent, USA), and DNA was quantified by using Quant-iT тм PicoGreen dsDNA Assay Kit (Life Technologies, USA). DNA was used for 454 pyrosequencing at the Gene Research Center at the University of Tsukuba on a GS Junior System (Roche Diagnostics, USA) in accordance with the manufacturer's instructions. A GS Junior Titanium emPCR Kit (Lib-L; Roche Diagnostics, USA) was used for library 
construction. The raw sequences were deposited in the Sequence Read Archive at the DNA Database of Japan (DDBJ) under accession no. DRA003055.

\section{4. 1. Processing of pyrosequencing reads}

The pyrosequencing reads were processed with the software package Claident ver 0.1.2014.02.06 (Tanabe and Toju, 2013). Raw reads were cleaned with trimming low-quality $3^{\prime}$ tail by using a minimum quality value of 27 (Kunin et al., 2010) and sorted by using sample-specific MIDs. The MID and forward primer $(545 \mathrm{~F})$ sequences attached to the 3 '-end were removed and the reads were filtered on the basis of length ( $\geq 350 \mathrm{bp}$ ). Then clustering was conducted within each sample on the basis of identity (cut-off of 97\%) by using the built-in assembler Assams v0.1.2013.08.10 (http://www.fifthdimension.jp/products/assams/; Toju et al., 2013). Next, low-quality and potentially chimeric reads were eliminated by using UCHIME v0.1.2013.0810 (Edgar et al., 2011) with the default settings. Cleaned reads were first clustered into contigs within each sample and then clustered into contigs across-sample; at both steps, an identity cut-off of $95 \%$ was used. The consensus sequence of each operational taxonomic unit (OTU) was assigned to taxonomic groups. Although the rarefaction curves drawn with the vegan package ver. 2.0 (Oksanen et al., 2008) in R (http://cran.rproject.org) showed that the OTU number was saturated for each sample (Fig. 3), the OTU number was affected by the total read number. To avoid this bias, 10,000 reads were randomly selected in triplicates. In each sample, singleton in each library was removed as artifactual sequences (Tedersoo et al., 2010).

\section{4. 2. Taxonomic assignment of picoeukaryotes}

The consensus sequence of each OTU was aligned to non-redundant alignment of 18S rRNA genes (SSU Ref_NR_99 ver. 115, SILVA database, Quast et al., 2013) by using the First Aligner tool in the ARB software package (Ludwing et al., 2004); the alignment was corrected manually where necessary. The aligned sequences were added to a guide tree without allowing change in the overall topology using the ARB Parsimony tool, and taxonomy was determined according to the classification ranks maintained by the Eukaryotic Taxonomy Working Group of the SILVA project. Representative nucleotide sequences of OTUs were also compared with known nucleotide sequences of cultured eukaryotes in the non-redundant (nr) database by using the Basic Local Alignment Search Tool (BLAST; Altschul et al., 1997; http://blast.st-va.ncbi.nlm.nih.gov/Blast.cgi).

\section{4. 3. Diversity and OTU composition analysis}

Diversity was evaluated by the index of the inverse of Simpson's index $\left(D_{\mathrm{s}}^{-1}\right)$ using the vegan package (Oksanen et al., 2008). The OTUs richness was evaluated by both nonparametric richness indices (ACE and Chao1) and parametric richness estimation (Bunge et al., 2012). The patterns of OTU composition were compared between treatments and between sites on the basis of the abundance of 10,000 reads. The distance of the OTU pattern between samples was measured by their correlation and clustered by Ward's minimum variance with multiscale bootstrap resampling (2,000 replications) using the package pvclust ver. 1.2 (http://www.sigmath.es.osaka-u.ac.jp/shimo-lab/prog/pvclust/).

\section{5. Comparison of culture strain cells before and after cryopreservation}


Skeletonema menzelii NIES-2842 (Heterokontophyta), Karlodinium veneficum NIES-1966 (Dinophyta), and Rhodomonas duplex NIES-765 (Cryptophyta) were obtained from the Microbial Culture Collection, National Institute for Environmental Studies (NIES), Japan (http://mcc.nies.go.jp/). Each strain was cultured in a $10 \mathrm{ml}$ medium and an aliquot containing intact cells was analyzed by FCM as described in section 2.2, and by light microscope (BX51; Olympus, Japan). The rest of the culture (ca. $6 \mathrm{ml}$ ) was cryopreserved and thawed as described in section 2.1. Optical characteristics of the cells were analyzed by FCM and their condition and morphology were analyzed by light microscopy as above. Images were captured with a digital camera (DP72; Olympus, Japan) and saved as digital files.

\section{Results and discussion}

\section{1. Estimation of diversity of picoeukaryotic assemblages}

Four amplicon libraries were constructed, and a total of 116,806 reads were obtained in our pyrosequencing runs (Table 1). After the removal of low-quality and potentially chimeric sequences, we obtained 10,088-37,454 reads in each library. 10,000 reads were randomly selected from each library and pooled for subsequent analysis. After singleton removal, 39,689 reads were grouped into 72 eukaryotic OTUs. Of these OTUs, 26 were found in C05F, 29 in C05NF, 36 in C12F, and 38 in C12NF (Table 2). The rarefaction curves of those OTUs plateaued in all the samples (Fig. 3), indicating that the number of reads was sufficient for analyzing the diversity of picoeukaryotes in samples containing 2,500 cells.

The inverse of Simpson's index $\left(D_{\mathrm{s}}^{-1}\right)$ was calculated for each data set and their combinations to compare the photosynthetic picoeukaryote diversities (Table 2). The highest index value (14.6) was obtained for a combination of all 39, 689 sequences and 72 OTUs. The diversity indices were 11.0 in C5 and 8.8 in C12, followed by the indices of individual samples, which ranged from 6.0 to 8.6. In the case of parametric richness and nonparametric richness (ACE and Chao1), similar to the number of OTUs, the values of fresh samples were higher than those of cryopreserved samples. Nonparametric richness indices has been used in a limited number of studies to assess picoeukaryotic diversity (Cheung et al., 2010; Massana et al., 2004). Chao1 and ACE values, which estimate the total number of OTUs, are usually 2-5 times the number of OTUs observed (Countway et al., 2007; Cheung et al., 2010). However, both of our values were similar to, or slightly higher than, the number of OTUs. This also confirms that the size of our samples was sufficient to assess biodiversity. Marie et al. (2010) examined sequence diversity in 18S rRNA clone libraries constructed from sorted populations of picoeukaryotes and nanoeukaryotes. The percentages of sequences from both size fractions increased with the number of sorted cells and suggested that the OTUs of dominant groups started to saturate between 1,000 and 10,000 cells, whereas samples with less than 1,000 picoeukaryotes or 100 nanoeukaryotes were contaminated with fungi. A dominant species of Bathycoccus was detected in a sorted sample of 1,000 cells but disappeared in sorted samples with larger cell numbers. This result may indicate that certain dominant species with low affinity for the primer set can be amplified only under noncompetitive conditions. Samples with larger cell numbers may not always provide accurate results in covering the whole biodiversity. For comparative analysis of biodiversity, the number of sorted cells needs to be optimized. 


\section{2. Taxonomic composition of amplicon libraries}

Trimmed contigs were grouped into at least 9 supergroup or division level (Fig. 4). The data on BLAST top hits (83\%-99\% identity) for the 72 OTUs are summarized in Table 3. Possible photosynthetic groups corresponded to 40 OTUs ( $81 \%$ reads), whereas the rest of the reads and OTUs corresponded to possible colorless groups which devoid their chloroplast. The most representative photosynthetic groups were Heterokontophyta (possible photosynthetic stramenopiles; 20 OTUs, 17,118 reads), followed by Cryptophyta (9 OTUs, 11,498 reads), Chlorophyta (5 OTUs, 1,245 reads), Dinophyta (5 OTUs, 2,234 reads), and Haptophyta (1 OTU, 65 reads). The colorless protist groups were Syndiniales of the Dinophyta (13 OTUs, 4,397 reads), Opisthokonta (3 OTUs, 11 reads), Rhizaria (7 OTUs, 2,891 reads), possible colorless chrysophytes (2 OTUs, 32 reads), and other stramenopiles (7 OTUs, 198 reads). Some phytoplankton could be engulfed by colorless protists and maintain similar fluorescence signals even inside predator cells during FCM sorting.

More than half of Heterokontophyta were diatoms, including small chain-forming species such as Skeletonema and Chaetoceros. These are typical phytoplankton species in Japanese coastal waters (Yamada et al., 2014), and Skeletonema reads were the most abundant in all samples. Colony and cell sizes are variable in such diatoms, and possible colony breakdown may have resulted in large numbers of individual cells in our samples. Bolidomonas and Pelagomonas-well-known picophytoplanktonic heterokontophytes (Vaulot et al., 2008) — were detected more sporadically. Phaeoplaca (contig 27; Table 3) was also found in the C5 sample with relatively high read numbers. Paraphysomonas species (contigs 31 and 55) are heterotrophic chrysophytes characterized by secondary loss of chloroplasts (Presig and Hibberd, 1983). Stramenopiles, including Labyrinthulomycetes, Pseudofungi, and marine stramenopile (MAST), were sporadically found in all samples.

Cryptophyta were the second dominant group. Geminigera (contigs 19 and 84) and Teleaulax (contigs 7 and 8) were identified in all samples. Although chlorophyte reads were not abundant, 5 distinct OTUs were reliably identified. Among chlorophyte OTUs, contig 26 showed 99\% identity with Bathycoccus prasinos, a well-known widespread picophytoplankton species (Vaulot et al., 2008); this is the first record of this species from the Japanese coast. Photosynthetic dinophytes were sporadically recognized in samples. Contig 5 (98\% identity to Karlodinium) showed high read numbers in C05F and C12NF. Colorless dinoflagellates belonging to the genus Amoebophrya (8799\% identity, Syndiniales, Dinophyta) were also found in C5 and C12 with high read numbers in fresh samples. The members of Syndiniales may have been sorted by FCM because they are wellknown parasites of photosynthetic organisms (Guillou et al., 2008).

The remaining relatively minor groups were Opisthokonta, Rhizaria, and Haptophyta. Opisthokonta OTUs had a small number reads and were related to metazoans (Hydrozoa), colorless protists (Ichthyosporea), and fungi (Basidiomycota). The Rhizaria includes three groups of amoeboid organisms, namely Cercozoa, Radiolaria, and Foraminifera. Six OTUs belonged to Cercozoa and one to Radiolaria. Interestingly, the haptophyte OTU (contig 23) showed 99\% identity with a symbiont of radiolaria. Host radiolarian cells can break and release symbiont cells during filtration through a plankton net and FCM analysis. Broken cells of either Cercozoa or Radiolaria may contaminate samples for DNA analysis. We confirmed that FCM cell sorting allows efficient genetic analysis of target picophytoplankton groups even in cryopreserved specimens, as it reduced contamination with heterotrophic protists in 18S rRNA gene amplicon libraries in the previous papers (Shi et al., 2009; 
Marie et al., 2010).

\section{3. Comparison of picoeukaryote diversity in samples before and after cryopreservation}

Cluster analysis of eukaryotic OTUs for each library indicated significant differences $(P<0.05)$ in OTU composition between the C5 and C12 sites with high bootstrap values (Fig. 5). The results indicated that the OTU compositions were more similar between cryopreserved and fresh samples from the same site than between similarly treated C5 and C12 samples. We also compared the read numbers of major taxonomic groups for both cryopreserved and fresh samples, in which OTUs presenting more than 100 reads were selected as major groups (Table 3). 9 OTUs (contigs 1, 7, 8, 11, $12,19,82,83,84)$ belonging to photosynthetic stramenopiles (Bacillariophyceae), Cryptophyta, Dinophyta and Chlorophyta were common in both treatments.

A significant correlation between cryopreserved and fresh treatments was also suggested in correlation analysis for 6 major taxonomic groups, Alveolata, Chlorophyta, Cryptophyta, Rhizaria, photosynthetic stramenopiles (Heterokontophyta) and non-photosynthetic stramenopiles (Fig. 6, correlation coefficient: 0.81 ). The read numbers of photosynthetic stramenopiles and Alveolata were slightly higher in fresh samples than in cryopreserved samples, whereas those of non-photosynthetic stramenopiles, Cryptophyta, Chlorophyta, and Rhizaria were slightly lower. A significant correlation in major taxonomic groups between cryopreserved and fresh samples suggests the usefulness of cryopreservation for molecular genetic surveys of microbial biodiversity in environmental samples. Microbial biodiversity changes quickly after sample collection (Mangot et al., 2013). Preparing cryopreserved specimens would facilitate studies of the biodiversity of microorganisms. Our data indicate that cryopreservation followed by FCM cell sorting allows accurate and efficient identification of photosynthetic picoeukaryotes in environmental specimens. This would be a notable advantage comparing usual sample preparation for NGS. Filtrated samples stored in the deep freezer have been used for NGS analysis of aquatic microbial diversity. In such method, microorganisms on the filter were analyzed all together, while cell suspensions thawed from cryopreserved specimens can be used for FCM cell sorting with particular targets, and possibly morphological observations and culturing.

\section{4. Flow cytometric and light microscopic comparison of culture strain cells before and after cryopreservation}

Although the bias in OTU composition between cryopreserved and fresh samples was small in the major taxa (Fig. 4), there was a bias of read numbers in some OTUs (Table 2). We assumed that this result would be caused by treatment of cell cryopreservation as a reason. It is known that the efficiency of cryopreservation varies between algal species (Rhodes et al., 2006, Day, 2004): Cyanophyta and Chlorophyta are generally cryopreserved with high viability (Mori et al., 2002), whereas Heterokontophyta, Cryptophyta, and Dinophyta are hardly cryopreserved with low or no viability (Rhodes et al. 2006; Day, 2004). Thus, we compared cryopreservation experiments using culture strains not natural seawater samples to assess the effects of cryopreservation. We chose two culture strains, Skeletonema menzelii NIES-2842 (Heterokontophyta) and Karlodinium veneficum NIES-1966 (Dinophyta), because closely related OTUs with these two species were included and have great differences of the sequence read number in our analyses (e. g. contigs 5 and 18, respectively)(Table 3). Some OTUs belonging to Cryptophyta also had a strong read number bias 
(Table 3). However, appropriate strains were not available in the world culture collections and we therefore chose Rhodomonas duplex NIES-765 as a representative of the Cryptophyta.

We compared cells from cryopreserved and fresh samples by using FCM (Fig. 7) and light microscopy (Fig. 8). Eukaryotic cells were distinguished from bacterial contamination by comparing side-angle scatter (SS) and forward-angle scatter (FS) (data not shown). Cryopreservation of $S$. menzelii did not considerably affect the intensity of SS and chlorophyll autofluorescence (Figs. 7a, b), and no significant difference in cell morphology was detected (Figs. 8a, b, Table 4). Cryopreservation of $K$. veneficum slightly decreased the intensity of SS and did not change chlorophyll autofluorescence (Figs. 7c, d), but it deformed cells, which became smaller, possibly because of cryoprotectant effects (Fig. 8d, Table 4). Cryopreservation of $R$. duplex slightly decreased the intensity of SS, but increased chlorophyll autofluorescence (Figs. 7e, f). Although cryopreservation altered cell morphology beyond recognition (Fig. 8f), individual cells became large and rounded. Cells ranged from 12.7-16.7 $\mu \mathrm{m}$ in length and 6.0-8.0 $\mu \mathrm{m}$ in width before cryopreservation (Fig. 8e, Table 4) and from 17.3-31.0 $\mu \mathrm{m}$ in length and 13.7-25.3 $\mu \mathrm{m}$ in width after cryopreservation (Fig. 8f, Table 4).

After cryopreservation, the cell size and morphology of the three species did not change uniformly, but even $R$. duplex showed only a small difference in FCM cytograms despite drastic changes in cell appearance. Most cells looked as though they were close to bursting, but they did not disintegrate and their chlorophyll fluorescence resembled that of living cells in cytograms. The cell density of $R$. duplex was not affected by cryopreservation. If other members of the Cryptophyta also do not disintegrate upon cryopreservation, this may explain why we detected them in all samples. However, it should be noted that a small shift in cytograms may generate a species (OTU) composition bias. Because environmental specimens contain diverse microorganisms with different cell densities and in different cell states (such as at different stages of the cell cycle), small changes in cytograms may affect the results of genetic studies. Accumulating data on cytogram shifts before and after cryopreservation would help to reduce such bias. Another way to reduce bias would be to increase the number of cells for sorting or enlarge the gate setting for FCM sorting, or both, although this might increase the number of contaminating cells. We need more reciprocal trials with different culture strains and environmental specimens to optimize the settings.

\section{Conclusions}

We applied cryopreservation to environmental specimens from the Japanese coast and investigated the diversity of picophytoplankton. Significant differences in the diversity of major OTUs were not observed between specimens before and after cryopreservation. By using three representative culture strains, we confirmed that the cytograms before and after cryopreservation showed only small differences. Genetic analysis of cryopreserved environmental specimens should allow repeated experiments for the same specimens, facilitating a more detailed investigation of microbial biodiversity.

\section{Funding}

This study was supported by JST, CREST and partly supported by NIES. 


\section{Author's contributions}

MK and HY conceived and designed the study. AK took seawater samples. MK, HY, and MHN performed cryopreservation. MS, HY and MD analyzed cells and conducted flow cytometric cell sorting. HY and TK performed molecular experiments for 454 pyrosequencing. TK analyzed the sequence data. HY took photos of the cells. MK, TK, MS and HY wrote and approved the paper.

\section{Acknowledgments}

This study was supported by JST, CREST and partly supported by NIES. Our use of the GS Junior System was supported by the Japan Advanced Plant Science Network and Gene Research

Center, the University of Tsukuba. We would like to thank Daniel Vaulot for comments and discussions on the initial stage of our works. 


\section{References}

Altschul, S.F., Madden, T.L., Schäffer, A.A., Zhang, J.H., Zhang, Z., Miller, W., Lipman, D.J., 1997. Gapped BLAST and PSI-BLAST: a new generation of protein database search programs. Nucleic Acids Res. 25, 3389-3402.

Bunge, J., Woodard, L., Böhning, D., Foster, J.A., Connolly, S., Allen, H.K., 2012. Estimating population diversity with CatchAll. Bioinformatics 28, 1045-1047.

Cheung, M.K., Au, C.H., Chu, K.H., Kwan, H.S., Wong, C.K., 2010. Composition and genetic diversity of picoeukaryotes in subtropical coastal waters as revealed by 454 pyrosequencing. ISME J. 4, 1053-59.

Countway, P.D., Gast, R.J., Dennett, M.R., Savai, P., Rose J.M. and Caron, D.A., 2007. Distinct protistan assemblages characterize the euphotic zone and deep sea $(2500 \mathrm{~m})$ of the western North Atlantic (Sargasso Sea and Gulf Stream). Environ. Microb. 9, 1219-1232.

Day, J.G., 2004. Cryopreservation: fundamentals, mechanisms of damage on freeze/thawing and application in culture collections. Nova Hedwigia 79, 191-205.

Edgar, R.C., Haas, B.J., Clemente, J.C., Quince, C., Knight, R., 2011. UCHIME improves sensitivity and speed of chimera detection. Bioinformatics 27, 2194-2200.

Gómez-Pereira, P.R., Kennaway, G., Fuchs, B.M., Tarran, G.A., Zubkov, M.V. 2013. Flow cytometric identification of Mamiellales clade II in the Southern Atlantic Ocean. FEMS Microbiol. Ecol. $83,664-671$.

Guillou, L., Viprey, M., Chambouvet, A., Welsh, R.M., Kirkham, A.R., et al. 2008. Widespread occurrence and genetic diversity of marine parasitoids belonging to Syndiniales (Alveolata). Environ.Microbiol. 10, 3349-65.

Hamdi, I., Denis, M., Bellaaj-Zouari, A., Khemakhem, H., Bel Hassen, M., Hamza, A., Barani, A., Bezac, C., Maalej, S., 2015. The characterization and summer distribution of ultraphytoplankton in the Gulf of Gabès (Eastern Mediterranean Sea, Tunisia) by using flow cytometry. Cont. Shelf Res. 93, 27-38.

Jardillier, L., Zubkov, M.V., Pearman, J., Scanlan, D.J., 2010. Significant $\mathrm{CO}_{2}$ fixation by small prymnesiophytes in the subtropical and tropical northeast Atlantic Ocean. ISME J. 4, 1180 1192.

Kunin, V., Engelbrektson, A., Ochman, H., Hugenholtz, P., 2010. Wrinkles in the rare biosphere: pyrosequencing errors can lead to artificial inflation of diversity estimates. Environ. Microbiol. $12,118-123$

Ludwig, W., Strunk, O., Westram, R., Richter, L., Meier, H., Yadhukumar, Buchner, A., Lai, T., Steppi, S., Jobb, G., Förster, W., Brettske, I., Gerber, S., Ginhart, A.W., Gross, O., Grumann, S., Hermann, S., Jost, R., König, A., Liss, T., Lüßmann, R., May, M., Nonhoff, B., Reichel, B., Strehlow, R., Stamatakis, A., Stuckmann, N., Vilbig, A., Lenke, M., Ludwig, T., Bode, A., Schleifer, K.H., 2004. ARB: a software environment for sequence data. Nucleic Acids Res 32, $1363-1371$.

Mangot, J.-F., Domaizon, I., Taib, N., Marouni, N., Duffaud, E., Bronner, G., Debroas, D., 2013. Short-term dynamics of diversity patterns: evidence of continual reassembly within lacustrine small eukaryotes. Environ. Microbiol. 15, 1745-1758.

Marie, D., Shi, X.L., Rigaut-Jalabert, F., Vaulot, D., 2010. Use of flow cytometric sorting to better 
assess the diversity of small photosynthetic eukaryotes in the English Channel. FEMS Microbiol. Ecol. 72, 165-178.

Massana, R., Balagué, V., Guillou, L., Pedrós-Alió, C., 2004. Picoeukaryotic diversity in an oligotrophic coastal site studied by molecular and culturing approaches. FEMS Microbiol. Ecol. 50, 231-43.

Massana, R., 2011. Eukaryotic Picoplankton in Surface Oceans. Annu. Rev. Microbiol. 65, 91-110.

Mori, F., Erata, M., Watanabe, M.M., 2002. Cryopreservation of cyanobacteria and green algae in the NIES-Collection. Microbiol. Cult. Coll. 18, 45-55.

Morris, G.J., 1981. Cryopreservation. An introduction to cryopreservation in culture collections. Institute of Terrestrial Ecology, Cambridge, UK. 27 pp.

Not, F., del Campo, J., Balagué, V., de Vargas, C., Massana, R., 2009. New insights into the diversity of marine picoeukaryotes. PLoS One 4, e7143.

Oksanen, J., Kindt, R., Legender, P., O'Hara, B., Simpson, G.L., Stevens, M.H.H., Wagner, H., 2008. vegan: Community Ecology Package, 1.13-1 ed.

Quast, C., Pruesse, E., Yilmaz, P., Gerken, J., Schweer, T., Yarza, P., Peplies, J., Glöckner, F.O., 2013. The SILVA ribosomal RNA gene database project: improved data processing and web-based tools. Nucleic Acids Res 41 (D1), D590-D596.

Paez, J.G., Lin, M., Beroukhim, R., Lee, J.C., Zhao, X.J., Richter, D.J., Gabriel, S., Herman, P., Sasaki, H., Altshuler, D., Li, C., Meyerson, M., Sellers, W.R., 2004. Genome coverage and sequence fidelity of phi 29 polymerase-based multiple strand displacement whole genome amplification. Nucleic Acids Res. 32, e71.

Preisig, H., Hibberd, D.J. 1983. Ultrastructure and taxonomy of Paraphysomonas (Chrysophyceae) and related genera. Nor. J. Bot. 3, 695-723.

Rhodes, L., Smith, J., Tervit, R., Roberts, R., Adamson, J., Adams, S., Decker, M. 2006. Cryopreservation of economically valuable marine micro-algae in the classes Bacillariophyceae, Chlorophyceae, Cyanophyceae, Dinophyceae, Haptophyceae, Prasinophyceae, and Rhodophyceae. Cryobiology 52, 152-156.

Shi, X.L., Marie, D., Jardillier, L., Scanlan, D.J., Vaulot, D., 2009. Groups without cultured representatives dominate eukaryotic picophytoplankton in the oligotrophic South East Pacific Ocean. PLoS One 4, e7657.

Tanabe, A.S., Toju, H., 2013. Two new computational methods for universal DNA barcoding: a benchmark using barcode sequences of bacteria, archaea, animals, fungi, and land plants. PloS One 8, e76910.

Tedersoo, L., Nilsson, R.H., Abarenkov, K., Jairus, T., Sadam, A., Saar, I., Bahram, M., Bechem, E., Chuyong, G., Köljalg, U., 2010. 454 Pyrosequencing and Sanger sequencing of tropical mycorrhizal fungi provide similar results but reveal substantial methodological biases. New Phytol. 188, 291-301.

Toju, H., Yamamoto, S., Sato, H., Tanabe, A.S., Gilbert, G.S., Kadowaki, K., 2013. Community composition of root-associated fungi in a Quercus-dominated temperate forest: "codominance" of mycorrhizal and root-endophytic fungi. Ecol. Evol. 3, 1281-1293.

Vaulot, D., Eikrem, W., Viprey, M., Moreau, H., 2008. The diversity of small eukaryotic phytoplankton $(\leq 3 \mu \mathrm{m})$ in marine ecosystems. FEMS Microbiol. Rev. 32:795-820. 
Worden, A.Z., Not, F., 2008. Ecology and diversity of picoeukaryotes. In Microbial Ecology of the Oceans, Second Edition, ed. DL Kirchman, pp. 159-196. New York, Wiley.

Worden, A.Z., Nolan, J.K., Palenik, B., 2004. Assessing the dynamics and ecology of marine picophytoplankton: the importance of the eukaryotic component. Limnol. Oceanogr. 49, 16879.

Yamada, M., Otsubo, M., Kodama, M., Yamamoto, K., Nishikawa, T., Ichimi, K., Tada, K., Harrison, P.J., 2014. Species composition of Skeletonema (Bacillariophyceae) in planktonic and restingstage cells in Osaka and Tokyo Bays. Plankton Benthos Res. 9, 168-175.

Zhang, L., Cui, X.F., Schmitt, K., Hubert, R., Navidi, W., Arnheim, N., 1992. Whole genome amplification from a single cell: implications for genetic analysis. Proc. Natl. Acad. Sci .USA 89, 5847-5851. 


\section{Figure legends}

Fig. 1. Flowchart illustrating the major steps of genetic analysis of photosynthetic pico- and nanophytoplankton with cryopreservation.

Fig. 2. Cytograms (side scatter vs. chlorophyll autofluorescence) of samples before and after cryopreservation. (a, b) Samples collected at C5. (c, d) Samples collected at C12. (a, c) Samples before cryopreservation; (b, d) samples after cryopreservation. Green color dots, sorted cells.

Fig. 3. Rarefaction curves of eukaryotic OTUs of the selected 10,000 reads.

Fig. 4. Taxonomic composition of eukaryotic OTUs assigned to supergroup or division level. Randomly selected 10,000 reads were used.

Fig. 5. Cluster analysis of dissimilarity among samples based on eukaryotic OTUs. Numbers on the nodes represent $p$-values computed with multiscale-bootstrap resampling (2,000 replications).

Fig. 6. Taxonomic differences (A) between samples before and after cryopreservation; (B) between C5 and C12.

Fig. 7. Cytograms (side scatter vs. chlorophyll autofluorescence) of three algal strains before and after cryopreservation. (a, b) Skeletonema menzelii (NIES-2842); (c, d) Karlodinium veneficum (NIES-1966); (e, f) Rhodomonas duplex (NIES-765). (a, c, e) Samples before cryopreservation; (b, d, f) samples after cryopreservation. Sensitivity was adjusted by using standard beads, Flow-Set Pro (Beckman Coulter). Red, eukaryotic algae; blue, contaminating bacteria.

Fig. 8. Light micrographs of three culture strains before and after cryopreservation. (a, b) Skeletonema menzelii (NIES-2842). (c, d) Karlodinium veneficum (NIES-1966). (e, f) Rhodomonas duplex (NIES765). (a, c, e) Samples before cryopreservation; (b, d, f) samples after cryopreservation. Photos were taken within $1 \mathrm{~h}$ after thawing of samples. Bars $=10 \mu \mathrm{m}$. 
Table 1. Treatment conditions and sequence summary.

\begin{tabular}{ccccc}
\hline & C05NF & C05F & C12NF & C12F \\
\hline Treatment & None & Cryopreservation & None & Cryopreservation \\
Final amplicon length (bp) & 675 & 753 & 689 & 662 \\
Total reads & 31,414 & 13,525 & 33,116 & 38,751 \\
Reads after trimming & 23,561 & 10,088 & 30,123 & 37,454 \\
OTUs in total reads & 40 & 26 & 41 & 48 \\
Reads after removal of singletons from & 9,870 & 9,997 & 9,845 & 9,977 \\
subsets of \# in 10,000 reads & & & & 36 \\
OTUs in 10,000 read subsets & 29 & 26 & 38 & \\
\hline
\end{tabular}


Table 2. Diversity of picoeukaryote OTUs constructed by using a cut-off identity of $95 \%$ for each library.

\begin{tabular}{|c|c|c|c|c|c|c|}
\hline \multirow[b]{3}{*}{ Analyzed library } & \multirow[b]{3}{*}{ No. of OTUs* } & \multirow[b]{3}{*}{$D_{\mathrm{s}}^{-1 * *}$} & \multicolumn{4}{|c|}{ Richness } \\
\hline & & & \multicolumn{2}{|l|}{ Parametric } & \multicolumn{2}{|c|}{ Non-parametric } \\
\hline & & & Best model & $\mathrm{SE}$ & Chao1 & $\mathrm{ACE}$ \\
\hline $\mathrm{C} 05 \mathrm{NF}$ & 29 & 6.0 & 30.6 & 1.4 & 29 & 29 \\
\hline $\mathrm{C} 05 \mathrm{~F}$ & 26 & 8.1 & 26.8 & 1.0 & 26 & 26 \\
\hline $\mathrm{C} 12 \mathrm{NF}$ & 38 & 8.6 & 41.7 & 2.3 & 38 & 38 \\
\hline $\mathrm{C} 12 \mathrm{~F}$ & 36 & 6.0 & 38.8 & 2.1 & 36 & 36 \\
\hline $\mathrm{C} 05 \mathrm{NF}+\mathrm{C} 05 \mathrm{~F}$ & 43 & 11.0 & 46.3 & 2.9 & 43 & 43 \\
\hline $\mathrm{C} 12 \mathrm{NF}+\mathrm{C} 12 \mathrm{~F}$ & 50 & 8.8 & 51.6 & 1.3 & 50 & 50 \\
\hline Total & 72 & 14.6 & 76.1 & 2.7 & 72 & 72 \\
\hline
\end{tabular}

*After singleton was removed from each sample.

** $D_{\mathrm{s}}^{-1}$, the inverse of Simpson's index.

SE indicates standard error. 
Table 3. List of OTUs and their affiliations to supergroups; top BLAST hits with their accession numbers and affiliations at the division/phylum and class level; and read numbers in each sample.

\begin{tabular}{|c|c|c|c|c|c|c|c|c|c|c|}
\hline \multirow{3}{*}{ OTUs } & \multirow[b]{3}{*}{ Supergroup* } & \multicolumn{4}{|c|}{ BLAST top hit } & \multicolumn{5}{|c|}{ Read number } \\
\hline & & & & Accession & & Idendity & & & & \\
\hline & & Division/Phylum & Class (Order) & no. & strain & $(\%)$ & $\mathrm{C} 05 \mathrm{NF}$ & $\mathrm{C} 05 \mathrm{~F}$ & $\mathrm{C} 12 \mathrm{NF}$ & $\mathrm{C} 12 \mathrm{~F}$ \\
\hline \multirow[t]{2}{*}{ contig_15 } & Alveolata & Dinophyta & Dinophyceae & HM066998 & Brachidinium capitatum & 94 & 0 & 43 & 0 & 0 \\
\hline & & & & & Gymnodinium sp. QZ-2012 & & & & & \\
\hline \multirow[t]{2}{*}{ contig_11 } & Alveolata & Dinophyta & Dinophyceae & JQ639761 & voucher HBI:HB201110a & 98 & 0 & 12 & 161 & 43 \\
\hline & & & & & Heterocapsa pygmaea isolate & & & & & \\
\hline contig_58 & Alveolata & Dinophyta & Dinophyceae & EF492500 & CCMP1322 & 91 & 0 & 0 & 0 & 9 \\
\hline contig_5 & Alveolata & Dinophyta & Dinophyceae & JF790988 & Karlodinium micrum clone 1129 & 98 & 0 & 1398 & 547 & 9 \\
\hline \multirow[t]{2}{*}{ contig_68 } & Alveolata & Dinophyta & Dinophyceae & JF790988 & Karlodinium micrum clone 1129 & 93 & 0 & 0 & 12 & 0 \\
\hline & & & Dinophyceae & & & & & & & \\
\hline \multirow[t]{3}{*}{ contig_29 } & Alveolata & Dinophyta & (Syndiniales) & AF239260 & Amoebophrya sp. 'Dinophysis' & 96 & 665 & 0 & 0 & 0 \\
\hline & & & & & Amoebophrya sp. ex & & & & & \\
\hline & & & Dinophyceae & & Alexandrium affine strain & & & & & \\
\hline \multirow[t]{2}{*}{ contig_22 } & Alveolata & Dinophyta & (Syndiniales) & AY775284 & JH0210a & 89 & 528 & 0 & 4 & 4 \\
\hline & & & Dinophyceae & & Amoebophrya sp. ex & & & & & \\
\hline \multirow[t]{3}{*}{ contig_63 } & Alveolata & Dinophyta & (Syndiniales) & JX173254 & Alexandrium sp. isolate MS2 & 99 & 0 & 0 & 1811 & 0 \\
\hline & & & & & Amoebophrya sp. ex & & & & & \\
\hline & & & Dinophyceae & & Cochlodinium polykrikoides & & & & & \\
\hline \multirow[t]{3}{*}{ contig_77 } & Alveolata & Dinophyta & (Syndiniales) & KF791347 & isolate Yeosu small & 92 & 0 & 0 & 6 & 23 \\
\hline & & & & & Amoebophrya sp. ex & & & & & \\
\hline & & & Dinophyceae & & Cochlodinium polykrikoides & & & & & \\
\hline \multirow[t]{2}{*}{ contig_45 } & Alveolata & Dinophyta & (Syndiniales) & KF791347 & isolate Yeosu small & 87 & 0 & 2 & 2 & 0 \\
\hline & & & Dinophyceae & & Amoebophrya sp. ex Gonyaulax & & & & & \\
\hline contig_30 & Alveolata & Dinophyta & (Syndiniales) & AY775285 & polygramma strain GS0209a & 87 & 259 & 0 & 0 & 0 \\
\hline
\end{tabular}




\begin{tabular}{|c|c|c|c|c|c|c|c|c|c|c|}
\hline contig_21 & Alveolata & Dinophyta & $\begin{array}{l}\text { Dinophyceae } \\
\text { (Syndiniales) }\end{array}$ & AY775285 & $\begin{array}{l}\text { Amoebophrya sp. ex Gonyaulax } \\
\text { polygramma strain GS0209a }\end{array}$ & 91 & 49 & 0 & 0 & 65 \\
\hline contig_44 & Alveolata & Dinophyta & $\begin{array}{l}\text { Dinophyceae } \\
\text { (Syndiniales) }\end{array}$ & AF472553 & $\begin{array}{l}\text { Amoebophrya sp. ex } \\
\text { Karlodinium micrum }\end{array}$ & 97 & 0 & 0 & 909 & 5 \\
\hline contig_57 & Alveolata & Dinophyta & $\begin{array}{l}\text { Dinophyceae } \\
\text { (Syndiniales) }\end{array}$ & AF472553 & $\begin{array}{l}\text { Amoebophrya sp. ex } \\
\text { Karlodinium micrum }\end{array}$ & 94 & 0 & 0 & 0 & 34 \\
\hline contig_36 & Alveolata & Dinophyta & $\begin{array}{l}\text { Dinophyceae } \\
\text { (Syndiniales) }\end{array}$ & AF472553 & $\begin{array}{l}\text { Amoebophrya sp. ex } \\
\text { Karlodinium micrum }\end{array}$ & 95 & 13 & 0 & 0 & 0 \\
\hline contig_43 & Alveolata & Dinophyta & $\begin{array}{l}\text { Dinophyceae } \\
\text { (Syndiniales) }\end{array}$ & AY208893 & $\begin{array}{l}\text { Amoebophrya sp. ex } \\
\text { Karlodinium micrum }\end{array}$ & 88 & 10 & 0 & 0 & 0 \\
\hline contig_41 & Alveolata & Dinophyta & $\begin{array}{l}\text { Dinophyceae } \\
\text { (Syndiniales) }\end{array}$ & AY208893 & $\begin{array}{l}\text { Amoebophrya sp. ex } \\
\text { Karlodinium micrum }\end{array}$ & 92 & 4 & 0 & 0 & 0 \\
\hline & & & Dinophyceae & & Amoebophrya sp. ex & & & & & \\
\hline contig_48 & Alveolata & Dinophyta & (Syndiniales) & AY208893 & Karlodinium micrum & 98 & 0 & 0 & 2 & 2 \\
\hline contig_6 & Archaeplastida & Chlorophyta & Chlorophyceae & AB701508 & $\begin{array}{l}\text { Chlamydomonas parkeae } \\
\text { Bathycoccus prasinos isolate }\end{array}$ & 99 & 0 & 59 & 8 & 16 \\
\hline contig_26 & Archaeplastida & Chlorophyta & Mamiellophyceae & JX625115 & CCMP1898 & 99 & 51 & 0 & 4 & 39 \\
\hline contig_61 & Archaeplastida & Chlorophyta & Mamiellophyceae & X73999 & Mantoniell squamata & 99 & 0 & 0 & 0 & 14 \\
\hline contig_9 & Archaeplastida & Chlorophyta & Prasinophyceae & AB017127 & Pterosperma cristatum & 97 & 16 & 620 & 0 & 0 \\
\hline contig_83 & Archaeplastida & Chlorophyta & Prasinophyceae & JF794047 & $\begin{array}{l}\text { Pyramimonas sp. RCC2009 } \\
\text { Cryptomonas sp. M2195 }\end{array}$ & 99 & 9 & 94 & 260 & 55 \\
\hline contig_49 & & Cryptophyta & Cryptophyceae & AM396375 & nucleomorph & 86 & 0 & 0 & 3 & 2 \\
\hline contig_52 & & Cryptophyta & & EF195737 & Cryptophyta sp. CR-MAL03 & 99 & 0 & 2 & 0 & 0 \\
\hline contig_50 & & Cryptophyta & & EU024984 & Cryptophyta sp. FU44-30 & 91 & 0 & 0 & 42 & 16 \\
\hline contig_19 & & Cryptophyta & Cryptophyceae & DQ452092 & Geminigera cryophila & 91 & 2841 & 727 & 634 & 843 \\
\hline contig_84 & & Cryptophyta & Cryptophyceae & DQ452092 & Geminigera cryophila & 91 & 461 & 1979 & 327 & 427 \\
\hline contig_33 & & Cryptophyta & Cryptophyceae & AM901023 & $\begin{array}{l}\text { Hemiselmis cryptochromatica } \\
\text { nucleomorph }\end{array}$ & 99 & 2 & 0 & 0 & 0 \\
\hline
\end{tabular}




\begin{tabular}{|c|c|c|c|c|c|c|c|c|c|c|}
\hline \multirow{2}{*}{$\begin{array}{l}\text { contig_13 } \\
\text { contig_8 }\end{array}$} & & Cryptophyta & Cryptophyceae & HF952608 & reticulata nucleomorph & 93 & 0 & 493 & 8 & 2 \\
\hline & & Cryptophyta & Cryptophyceae & AJ421146 & Teleaulax amphioxeia & 99 & 41 & 830 & 68 & 175 \\
\hline & & & & & Teleaulax gracilis strain & & & & & \\
\hline contig_7 & & Cryptophyta & Cryptophyceae & JQ966995 & Cr7EHU & 99 & 83 & 709 & 260 & 523 \\
\hline contig_59 & Opisthokonta & Cnidaria & Hydrozoa & AF358073 & Muggiaea sp. AGC-2001 & 99 & 0 & 0 & 0 & 2 \\
\hline & & & & & Ichthyosporea sp. ATCC PRA- & & & & & \\
\hline contig_54 & Opisthokonta & Amoebidiozoa & Ichthyosporea & GU810144 & 279 & 97 & 0 & 0 & 0 & 3 \\
\hline & & & & & Leucogyrophana mollusca strain & & & & & \\
\hline contig_69 & Opisthokonta & Basidiomycota & Agaricomycetes & DQ534684 & DAOM138006 & 86 & 0 & 0 & 6 & 0 \\
\hline & & & Prymnesiophycea & & Haptophyte symbiont of & & & & & \\
\hline contig_23 & & Haptophyta & $\mathrm{e}$ & AB180202 & Dictyocoryne truncatum & 99 & 0 & 0 & 63 & 2 \\
\hline contig_65 & Rhizaria & Cercozoa & Imbricatea & AF411264 & Allas sp. (3108W2) & 84 & 0 & 0 & 70 & 0 \\
\hline contig_2 & Rhizaria & Radiozoa & Polycystinea & HQ651802 & Lithomelissa setosa isolate 2 & 99 & 0 & 13 & 0 & 0 \\
\hline contig_20 & Rhizaria & Cercozoa & Thecofilosea & DQ303923 & Ebria tripartita isolate 2 & 83 & 0 & 1788 & 0 & 0 \\
\hline contig_70 & Rhizaria & Cercozoa & Thecofilosea & DQ303923 & Ebria tripartita isolate 2 & 83 & 0 & 0 & 9 & 0 \\
\hline contig_75 & Rhizaria & Cercozoa & Thecofilosea & AB558956 & Mataza hastifera & 92 & 0 & 0 & 7 & 0 \\
\hline contig_39 & Rhizaria & Cercozoa & & FJ824128 & Cercozoa sp. CC-2009d & 84 & 973 & 0 & 0 & 0 \\
\hline & & & & & Cercozoan amoeba sp. ex & & & & & \\
\hline contig_67 & Rhizaria & Cercozoa & & DQ666485 & Porpyra yezoensis & 83 & 0 & 0 & 31 & 0 \\
\hline contig_62 & Stramenopiles:P & Heterokontophyta & Bacillariophyceae & AB847419 & Chaetoceros debilis & 99 & 0 & 0 & 0 & 278 \\
\hline & & & & & Chaetoceros muellerii clone & & & & & \\
\hline contig_17 & Stramenopiles:P & Heterokontophyta & Bacillariophyceae & JF790991 & 1133 & 99 & 52 & 0 & 159 & 0 \\
\hline & & & & & Chaetoceros muellerii clone & & & & & \\
\hline contig_14 & Stramenopiles:P & Heterokontophyta & Bacillariophyceae & JF790992 & 1134 & 97 & 0 & 69 & 0 & 184 \\
\hline contig_81 & Stramenopiles:P & Heterokontophyta & Bacillariophyceae & KJ671692 & Chaetoceros sp. 19 LG-2014 & 99 & 0 & 0 & 2 & 0 \\
\hline
\end{tabular}




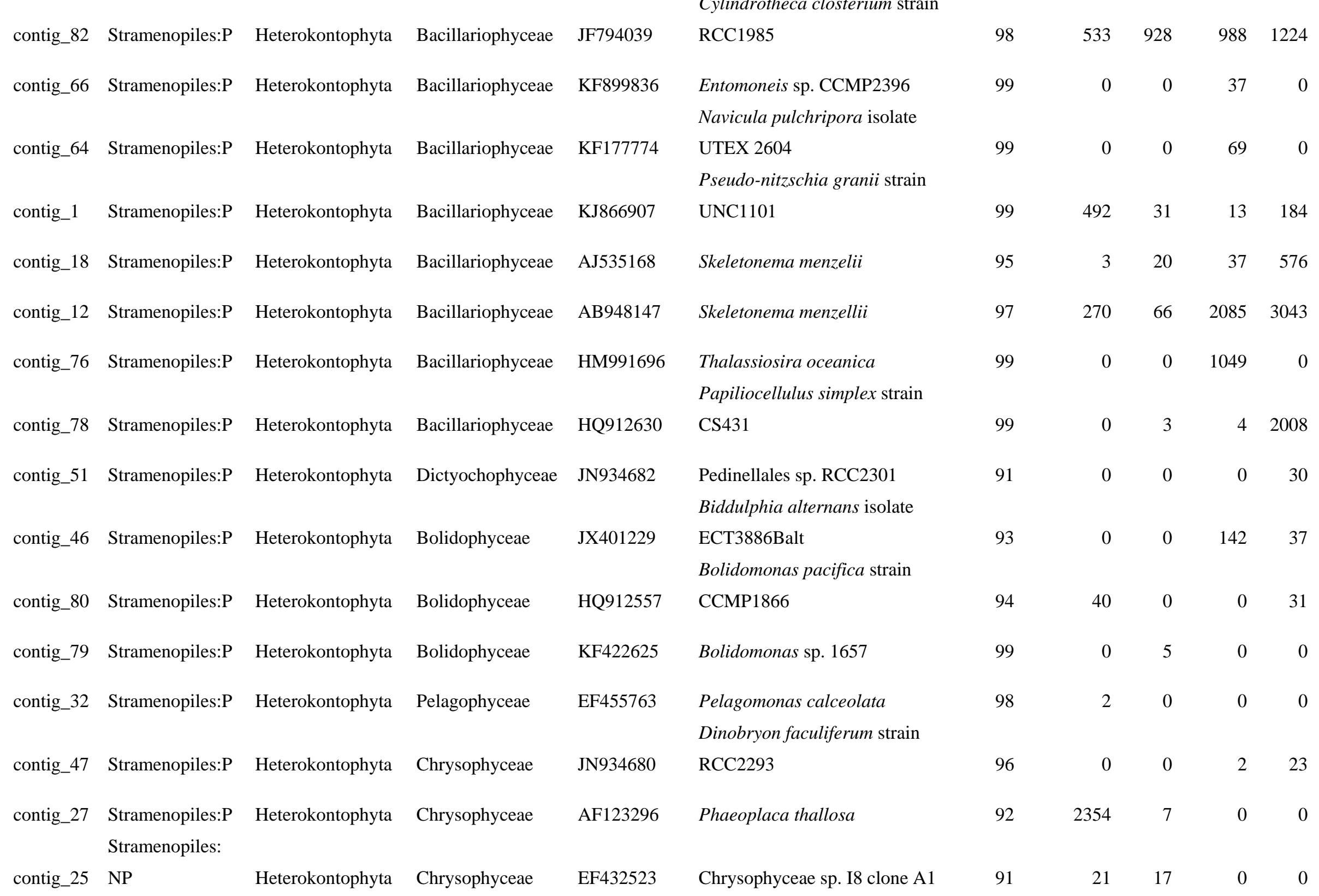


Stramenopiles:

\begin{tabular}{|c|c|c|c|c|c|c|c|c|c|c|}
\hline \multirow[t]{2}{*}{ contig_31 } & NP & Heterokontophyta & Chrysophyceae & AF109326 & Paraphysomonas butcheri & 89 & 2 & 0 & 0 & 0 \\
\hline & Stramenopiles: & & & & Paraphysomonas sp. 18 JMS- & & & & & \\
\hline \multirow[t]{2}{*}{ contig_55 } & $\mathrm{NP}$ & Heterokontophyta & Chrysophyceae & JQ967323 & 2012 & 99 & 0 & 0 & 0 & 30 \\
\hline & Stramenopiles: & Labyrinthulomyco & Labyrinthulomyce & & & & & & & \\
\hline \multirow[t]{2}{*}{ contig_53 } & $\mathrm{NP}$ & ta & tes & FJ799796 & Oblongichytrium sp. PBS02 & 87 & 0 & 0 & 0 & 16 \\
\hline & Stramenopiles: & Labyrinthulomyco & Labyrinthulomyce & & & & & & & \\
\hline \multirow[t]{2}{*}{ contig_37 } & $\mathrm{NP}$ & ta & tes & AY872271 & Thraustochytriidae sp. SW9 & 92 & 4 & 0 & 0 & 0 \\
\hline & Stramenopiles: & Labyrinthulomyco & Labyrinthulomyce & & & & & & & \\
\hline \multirow[t]{2}{*}{ contig_3 } & NP & ta & tes & GQ354272 & Oblongichytrium sp. PBS03 & 90 & 0 & 78 & 0 & 0 \\
\hline & Stramenopiles: & & & & & & & & & \\
\hline \multirow[t]{2}{*}{ contig_28 } & $\mathrm{NP}$ & Pseudofungi & & JF791043 & Pirsonia verrucosa clone 7535 & 96 & 16 & 0 & 0 & 0 \\
\hline & Stramenopiles: & Stramenopiles & & & & & & & & \\
\hline \multirow[t]{2}{*}{ contig_4 } & NP & Incertae sedis & Nanomonadea & JN848814 & Incisomonas marina strain BQ & 95 & 0 & 4 & 0 & 0 \\
\hline & Stramenopiles: & & & & & & & & & \\
\hline contig_38 & NP (MAST) & NA & NA & NA & MAST3 & - & 76 & 0 & 0 & 0 \\
\hline contig_74 & $\begin{array}{l}\text { Stramenopiles: } \\
\text { NP (MAST) }\end{array}$ & NA & NA & NA & MAST7 & - & 0 & 0 & 4 & 0 \\
\hline
\end{tabular}

* Affiliation to supergroups is indicated according to SSU Ref_NR_99 ver. 115, SILVA. P and NP, photosynthetic- and non-photosynthetic, respectively. MAST, uncultured marine stramenopiles. NA, not applicable (because the OTU belongs to MAST for which no cultured strains were reported).

NA indicates "not applied" because the OTU belonged to MAST in which no cultured strain was reported. 
Table 4. Cellular characteristics of cultured S. menzelii, K. veneficum, and $R$. duplex before and after cryopreservation.

\begin{tabular}{|c|c|c|c|c|c|c|c|c|c|}
\hline \multirow[b]{2}{*}{ Specific name } & \multirow[b]{2}{*}{ No. of strain } & & \multicolumn{3}{|c|}{ No cryopreservation } & \multicolumn{3}{|c|}{ Cryopreservation } & \multirow{2}{*}{$\begin{array}{c}\text { Cellular structural } \\
\text { change }\end{array}$} \\
\hline & & & $\begin{array}{l}\text { Range } \\
(\mu \mathrm{m})\end{array}$ & $\begin{array}{r}\text { Mean } \\
(\mu \mathrm{m})\end{array}$ & $\begin{array}{l}\text { No. of } \\
\text { cells }\end{array}$ & $\begin{array}{l}\text { Range } \\
(\mu \mathrm{m})\end{array}$ & $\begin{array}{l}\text { Mean } \\
(\mu \mathrm{m})\end{array}$ & $\begin{array}{l}\text { No. of } \\
\text { cells }\end{array}$ & \\
\hline \multirow[t]{2}{*}{ Skeletonema menzelii } & NIES-2842 & Length & nd & - & - & nd & - & - & Not changed \\
\hline & & Width & nd & - & & nd & - & & \\
\hline \multirow[t]{2}{*}{ Karlodinium veneficum } & NIES-1966 & Length & $10.3-17.7$ & 12.3 & 9 & $7.0-12.3$ & 10.2 & 13 & Changed \\
\hline & & Width & $7.3-12.3$ & 9.5 & 9 & $6.7-11.7$ & 8.7 & 13 & \\
\hline \multirow[t]{2}{*}{ Rhodomonas duplex } & NIES-765 & Length & $12.7-16.7$ & 15.4 & 8 & $17.3-13.0$ & 22.2 & 7 & Changed \\
\hline & & Width & $6.0-8.0$ & 7.7 & 8 & $13.7-25.3$ & 18.7 & 7 & \\
\hline
\end{tabular}

nd, not determined

n, number of measurement 
Sea water

\section{$\downarrow$}

Concentration of phytoplankton with TFF (tangential flow filtering)

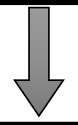

Cryopreservation

- Cryoprotectant: 5\%DMSO

- 2 step freezing method

- Stored in liquid $\mathrm{N}_{2}$

Flow cytometry cell sorting

- Chlorophyll $a$ fluorescence

- Cell size

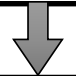

Extract genomic DNA

J

Amplification of target DNA

- Whole genome amplification

- 18S rDNA amplification

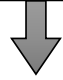

Amplicon analysis

- Next generation sequencing

- Processing, BLAST 


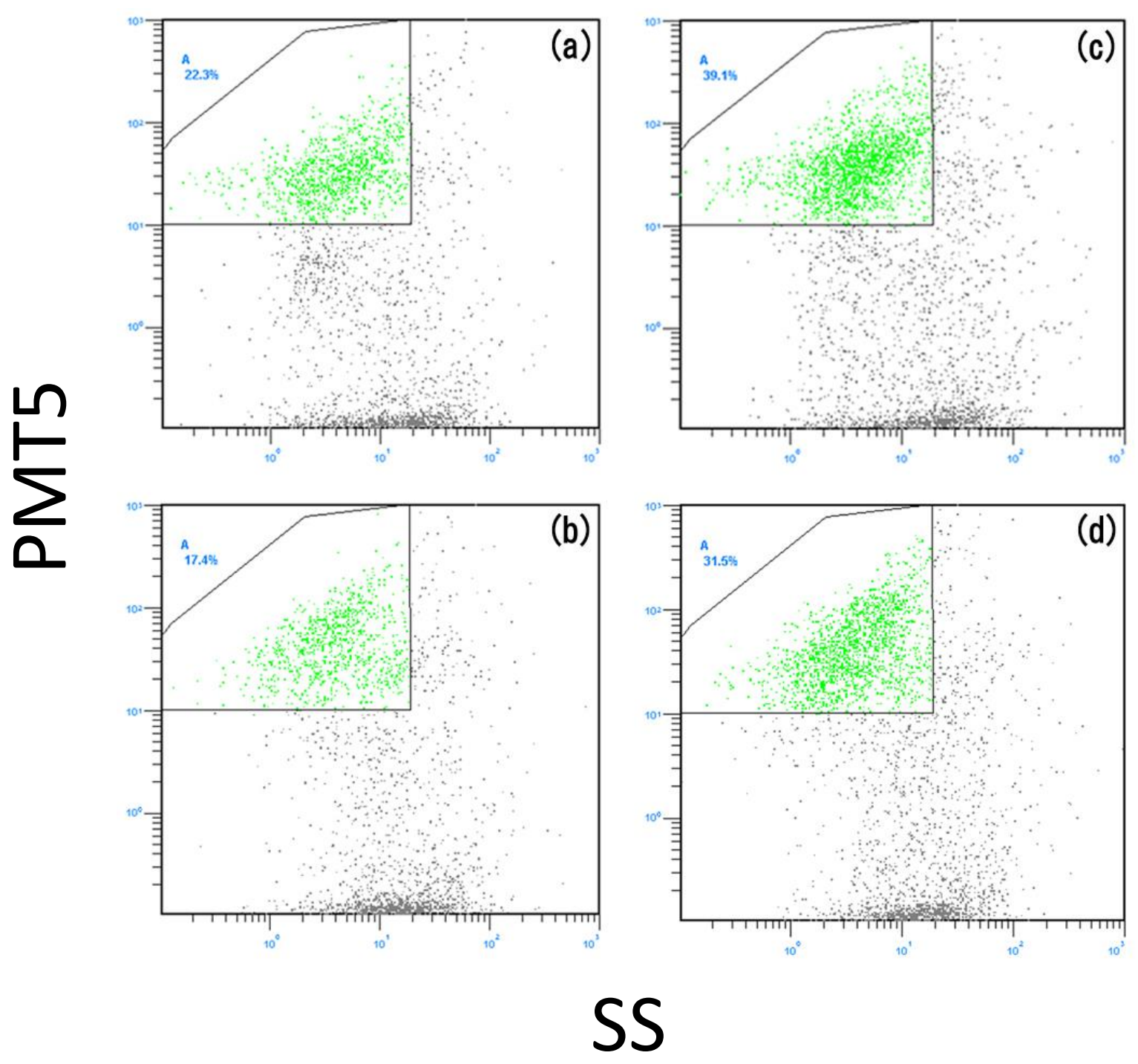

Fig. 2 


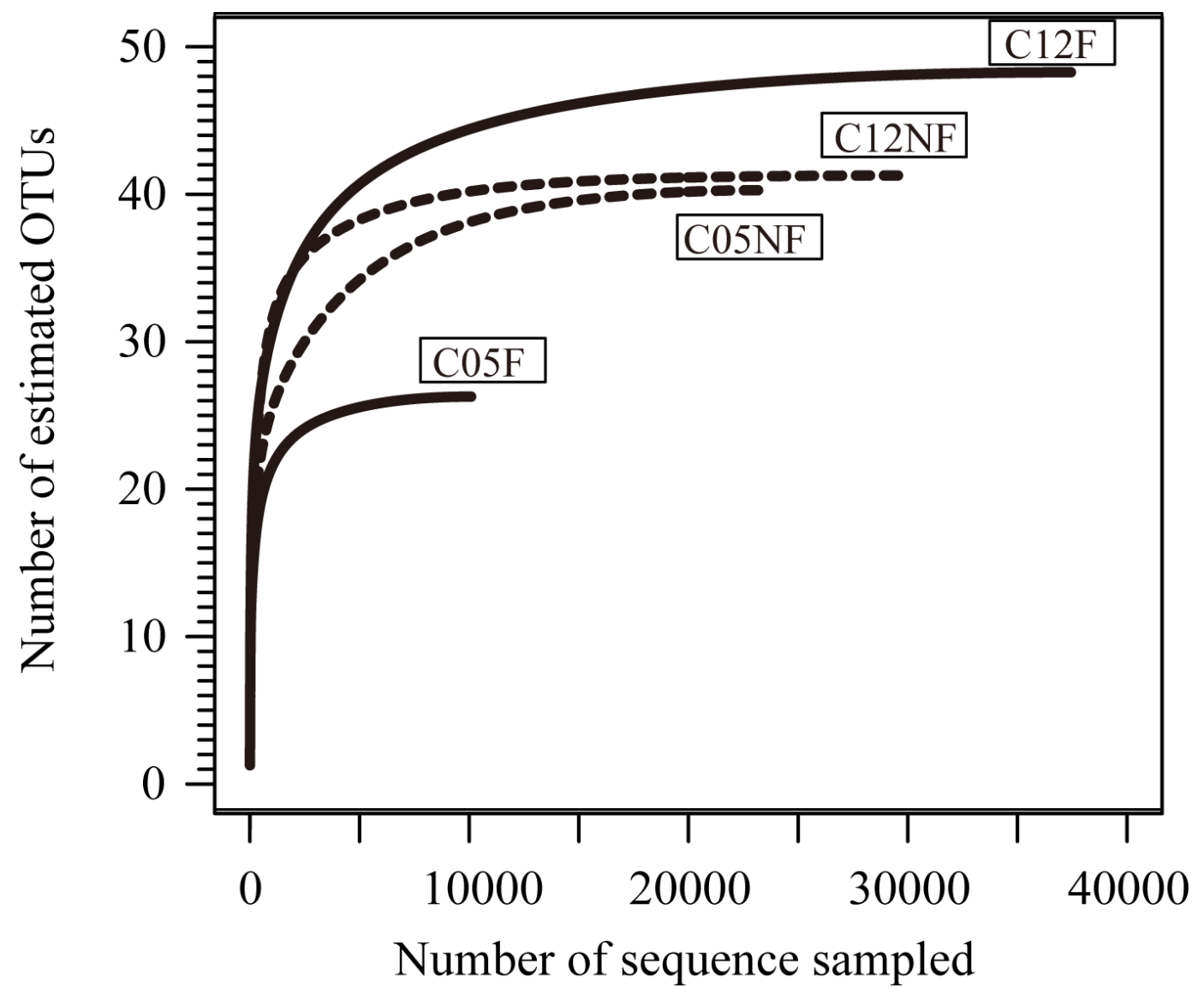

Fig. 3 


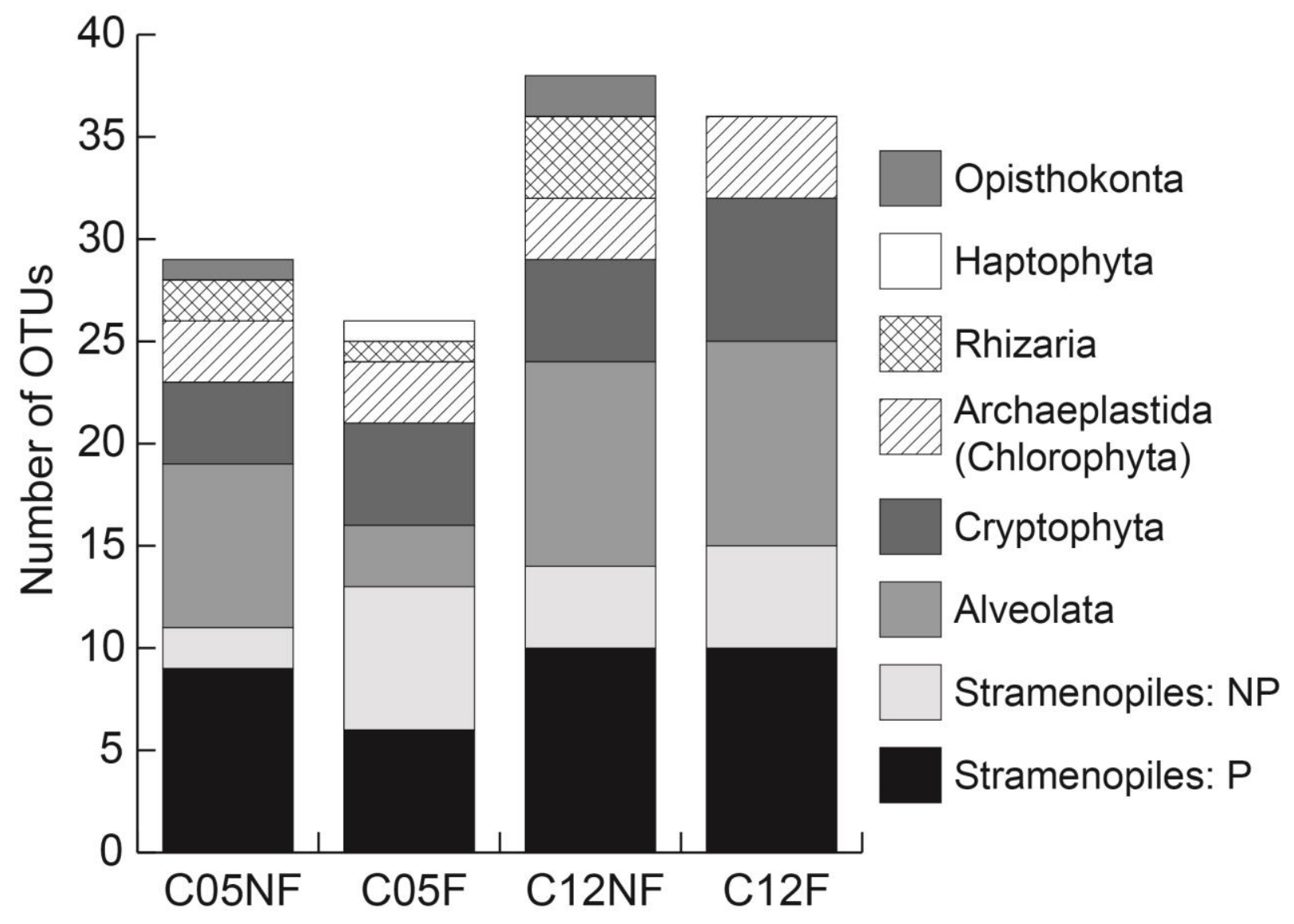

Fig. 4 


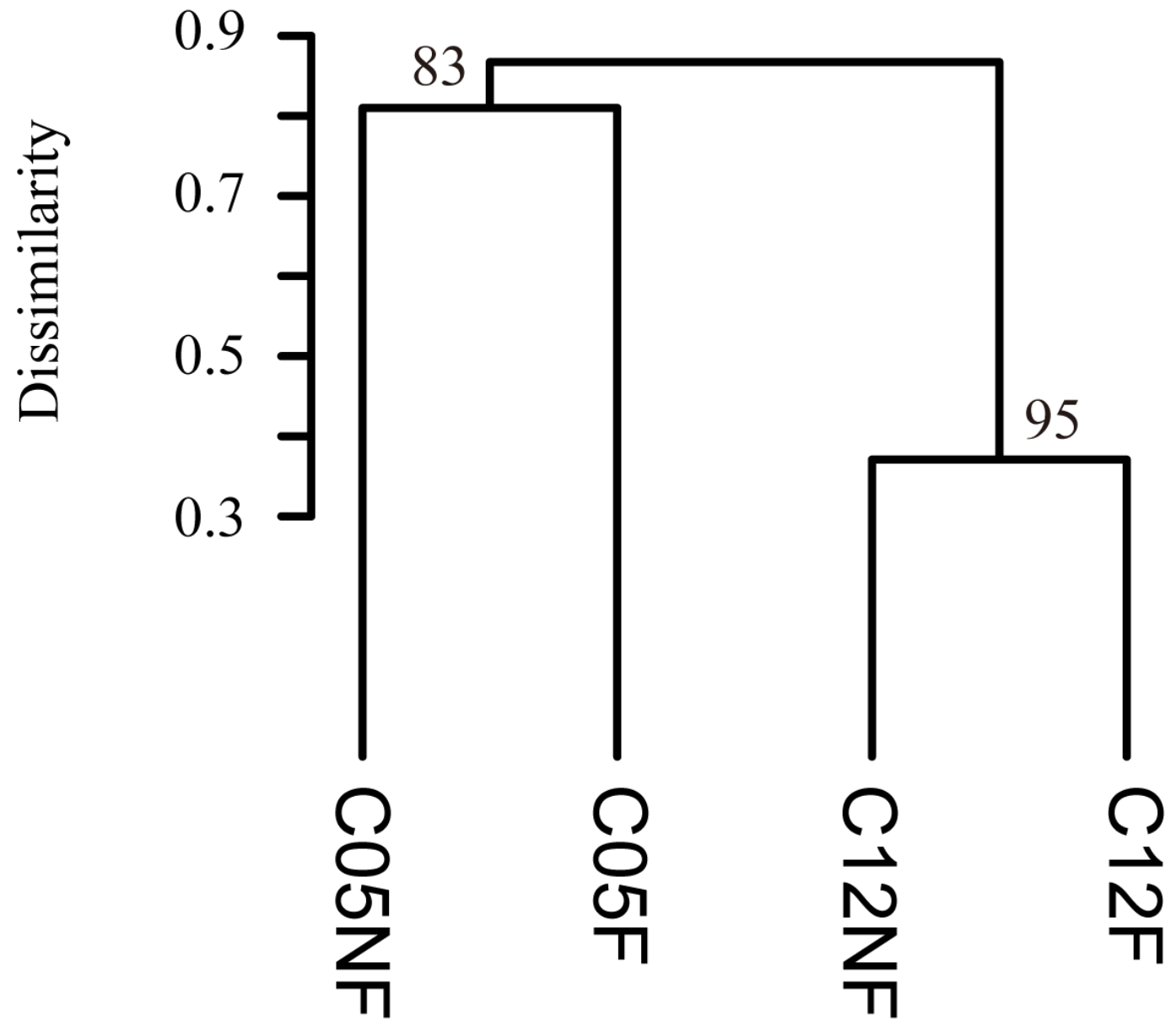

Fig. 5 


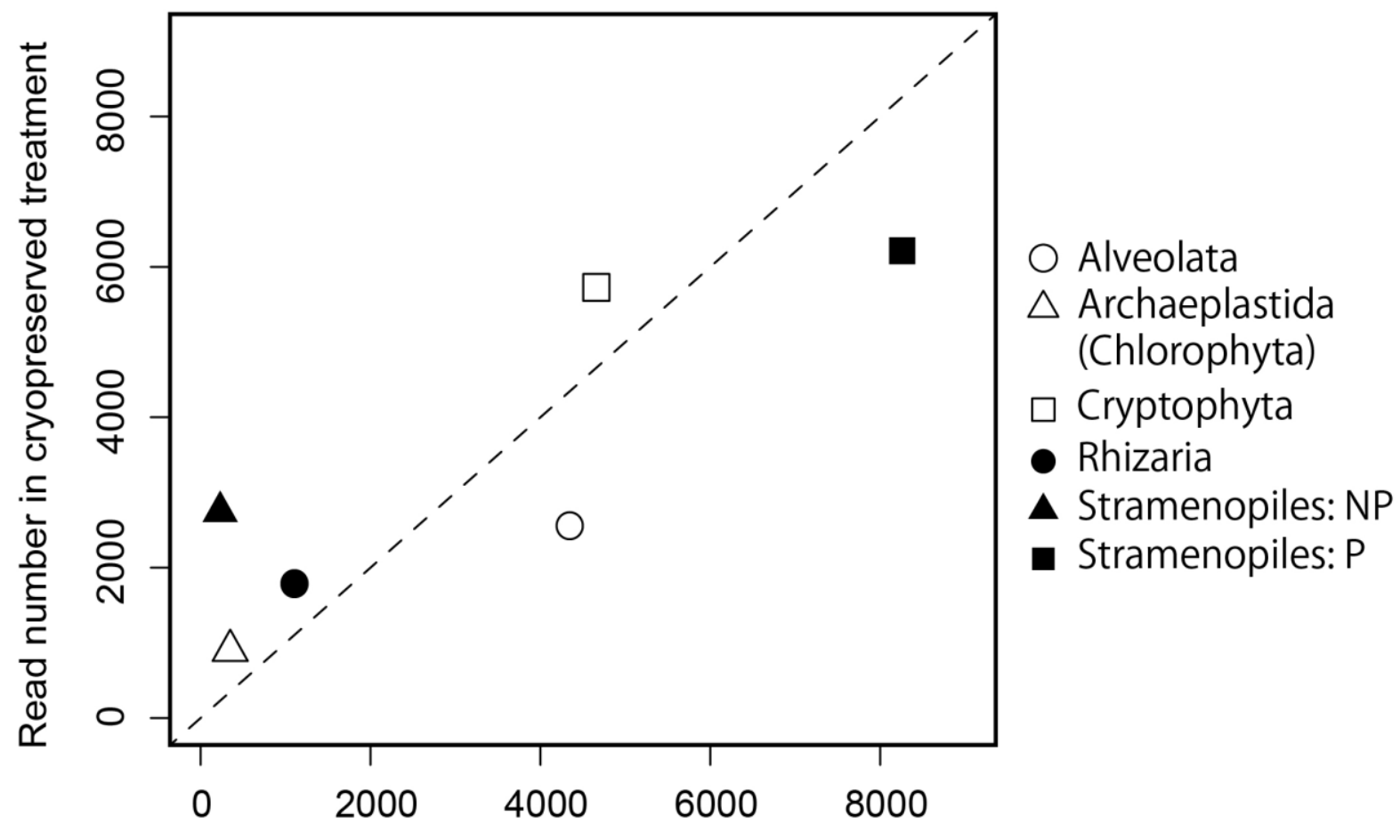

Read number in non-cryopreserved treatment 

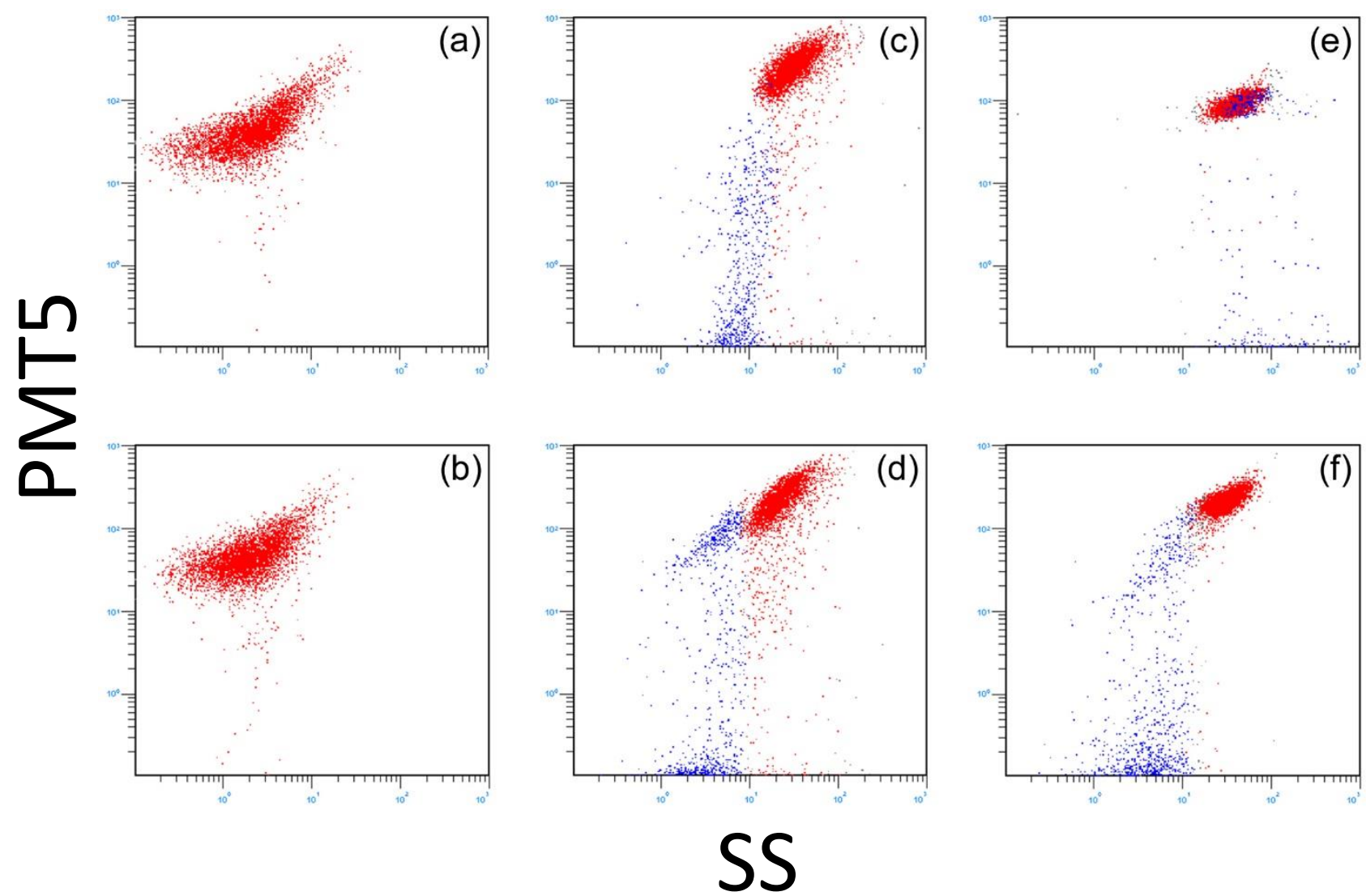

Fig. 7 

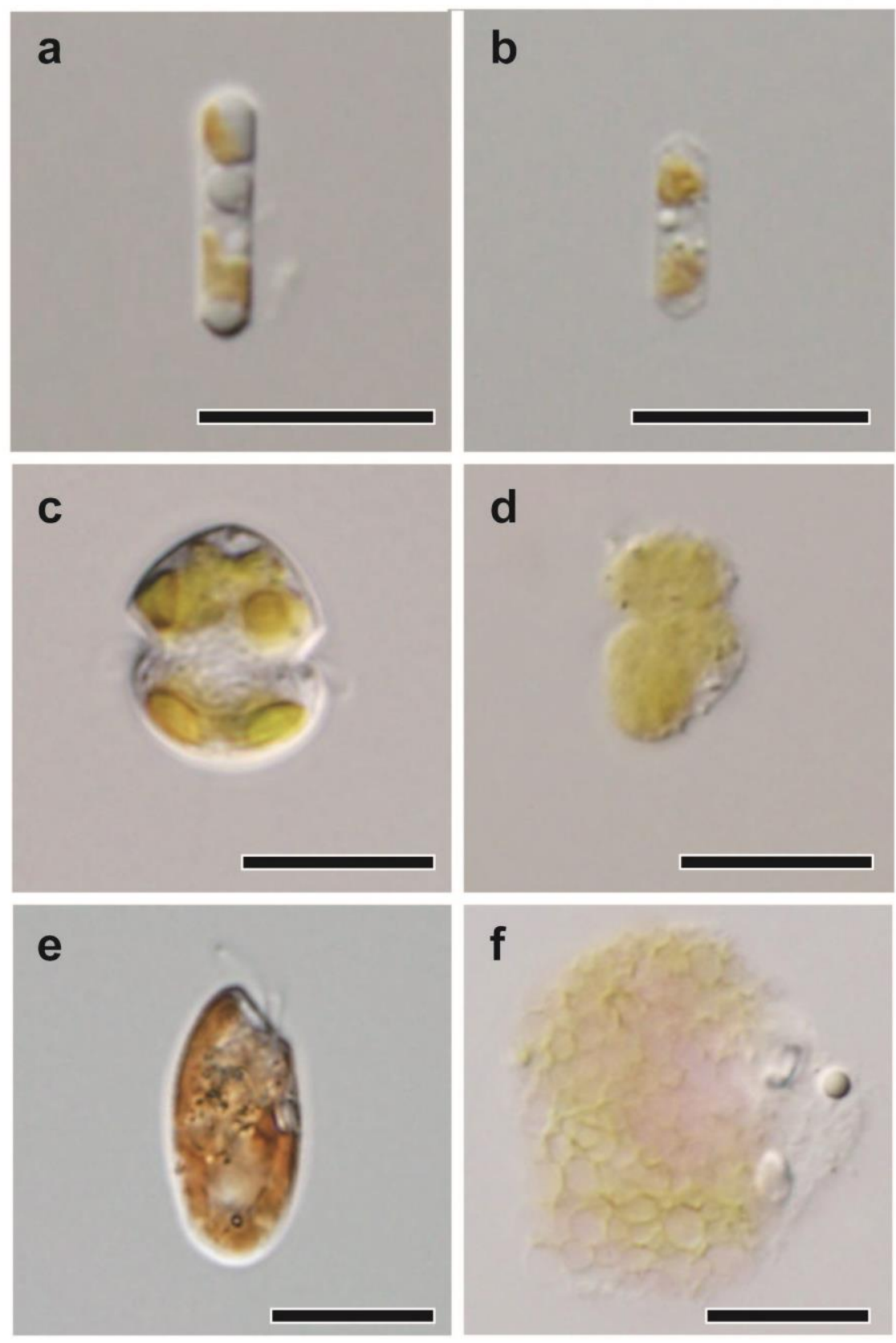

Fig. 8 